Gut, 1989, 30, 60-64

\title{
Pernicious anaemia and Campylobacter like organisms; is the gastric antrum resistant to colonisation?
}

\author{
J-F FLEJOU, P BAHAME, A C SMITH, R W STOCKBRUGGER, J RODE, \\ AND A B PRICE
}

From the Dept of Pathology, Northwick Park Hospital and Clinical Research Centre, Harrow, Middlesex, Hopital Beaujon, Service Central d'Anatomie Pathologique, Clichy Cedex, France, and The Bland Sutton Institute of Pathology, The Middlesex Hospital, London

SUMMARY Gastric biopsies from 86 patients with pernicious anaemia were examined for Campylobacter like organisms with particular attention to those showing an antral gastritis in addition to the usual pattern of body gastritis. All the patients had chronic atrophic gastritis in the body but Campylobacter like organisms were found at this site in only three patients. Thus the Type A pattern of gastritis (autoimmune) seen in patients with pernicious anaemia is only rarely associated with Campylobacter like organisms. Forty four of these patients had biopsies from body and antrum, 16 showed an antral gastritis of whom only one had Campylobacter like organism present. Twenty five of this latter group of patients were rebiopsied after five years. There was no change in the pattern of gastritis, and the same single patient remained colonised. The frequency of an antral gastritis in patients with pernicious anaemia was $36 \%$ yet the frequency of antral colonisation by Campylobacter like organisms was very low (6\%). These results show that, as in the body, Campylobacter like organisms are not associated with gastritis when it occurs at this site in pernicious anaemia. The antral gastritis that may accompany body gastritis in pernicious anaemia seems more likely therefore to be an extension of primary type $A$ body gastritis (autoimmune) rather than a secondary type B (chronic) gastritis and, it is argued, the antrum may exhibit resistance to colonisation.

Campylobacter pylori is strongly associated with gastritis. ${ }^{1-3}$ Of the main patterns of gastritis, ${ }^{4-6}$ the association of Campylobacter pylori is with type B. This corresponds approximately to the hypersecretory pattern described by Correa ${ }^{4}$ and is characterised by predominantly antral inflammation with extension into the body with age. Whether Campylobacter pylori is a pathogen rather than an opportunist is still disputed but the experimental production of gastritis in $\operatorname{man}^{7}$ and the pig $^{8}$ after ingestion of the organisms favours a pathogenic role. Its absence in patterns of gastritis other than type B might also be evidence in favour of a primary role. In this respect

Address for correspondence: Dr A B Price, Dept of Pathology, Northwick Park Hospital and CRC, Watford Rd, Harrow, Middlesex.

Received for publication 7 July 1988. the organisms are absent in the gastritis associated with bile reflux $x^{9}$ and probably in pernicious anaemia. Only limited correspondence ${ }^{1011}$ documents the situation in the latter, however, which is the major cause of type $\mathrm{A}^{4}$ or autoimmune ${ }^{5}$ gastritis. Here in the majority of cases the gastritis characteristically involves the body sparing the antrum. O'Connor $e t$ $a l^{10}$ found Campylobacter pylori in only three of 14 patients with pernicious anaemia, but the detailed location of colonisation and the state of the antrum were not made clear. When the antrum is normal in patients with pernicious anaemia a low frequency of Campylobacter pylori is to be expected for association with a normal mucosa is very rare. ${ }^{12}$ It is the frequency of Campylobacter pylori in those patients with pernicious anaemia who have antral inflammation that is of interest. Do such individuals simply 
have type B or hypersecretory gastritis superimposed on a type $\mathrm{A}$ or autoimmune pattern and with this a correspondingly high rate of Campylobacter pylori colonisation?

To answer this question this study looked at the Campylobacter status of a large number of patients with pernicious anaemia but in particular that group with an antral gastritis.

\section{Methods}

PATIENTS

Gastric biopsies from 86 patients with pernicious anaemia were studied. These were identified from the pathology records of Northwick Park Hospital and the Middlesex Hospital. The diagnosis of pernicious anaemia was based on the finding of a megaloblastic anaemia, a low serum $B_{12}$ and an abnormal Schilling test which corrected with intrinsic factor. The patients comprised 39 men and 47 women aged 20-88 (median age 58.6 years). Endoscopic biopsies from the gastric body were available in all patients and antral biopsies from 44 of these patients. Twenty five of this group of 44 patients were included in a follow up study for other reasons and a second series of body and antral endoscopic biopsies five years later were available.

Routine paraffin embedded $3 \mu \mathrm{m}$ sections were cut and stained with haematoxylin and eosin. Although organisms can be seen with this routine stain an additional cresyl fast violent stain was used to help identify Campylobacter like organisms. ${ }^{13}$ This has been shown to be a simple and reliable technique. Because of the absence of confirmatory microbiology in this study the term Campylobacter like organisms, rather than Campylobacter pylori, is used when referring to the histological findings. Chronic gastritis was classified according to the method of Whitehead ${ }^{14}$ and the polymorphonuclear leucocyte infiltrate and extent of intestinal metaplasia assessed in a simple semi-quantitative manner (Table 1). The Mann-Whitney U test was used for statistical analysis of the results.

\section{Results}

All patients had chronic atrophic gastritis of the body, and 16/44 (36\%) had an abnormal antral biopsy (Table 1). The grades of gastritis in the body did not differ in patients with a normal antral biopsy (two mild, 12 moderate, 12 severe body gastritis, and two unclassified) from those with an antral gastritis (one mild, six moderate, eight severe atrophic gastritis, and one unclassified). Intestinal metaplasia was common in the body but rare in the antrum (Table 1). There were no statistical differences
Table 1 Gastric histological findings in patients with pernicious anaemia

\begin{tabular}{llcc}
\hline & & Body & Antrum \\
\hline Patients (n) & & $86(3)$ & $44(1)$ \\
Normal mucosa & & 0 & 28 \\
Superficial gastritis & & 0 & 3 \\
Atrophic gastritis & mild & 5 & $7(1)$ \\
& moderate & $41(3)$ & 2 \\
Unsuitable for classification & 33 & 4 \\
Neutrophils & absent & $74(2)$ & 0 \\
& few & $12(1)$ & $40(1)$ \\
& moderate & 0 & 4 \\
& numerous & 0 & 0 \\
Intestinal metaplasia & absent & $26(1)$ & 0 \\
& mild & 28 & $38(1)$ \\
& moderate & $23(2)$ & 2 \\
& diffuse & 9 & 3 \\
\hline
\end{tabular}

() Campylobacter pylori positive patients.

Table 2 Five year histological follow-up in 25 patients with pernicious anaemia

\begin{tabular}{|c|c|c|c|c|}
\hline & \multicolumn{2}{|l|}{ Body } & \multicolumn{2}{|l|}{ Antrum } \\
\hline & $\begin{array}{l}\text { lst } \\
\text { biopsy }\end{array}$ & $\begin{array}{l}\text { 2nd } \\
\text { biopsy }\end{array}$ & $\begin{array}{l}\text { lst } \\
\text { biopsy }\end{array}$ & $\begin{array}{l}2 n d \\
\text { biopsy }\end{array}$ \\
\hline Normal mucosa & 0 & 0 & 19 & 19 \\
\hline Superficial gastritis & 0 & 0 & 3 & 2 \\
\hline Atrophic gastritis mild & 0 & 0 & $2(1)$ & $3(1)$ \\
\hline moderate & $11(1)$ & $10(1)$ & 0 & 0 \\
\hline severe & 11 & 15 & 1 & 1 \\
\hline Unsuitable for classification & 3 & 0 & 0 & 0 \\
\hline
\end{tabular}

() Campylobacter pylori positive patients.

between the ages of patients with mild/moderate and severe atrophic gastritis in the body, but patients with a normal antrum were significantly younger than patients with antral gastritis (20-79 years, median 53 , $v$ 34-88 years, median $69, \mathrm{p}<0 \cdot 05)$. Campylobacter like organisms were seen in the body in only three of the 86 patients (Table 1) of whom one was from the group of 44 in whom there was also an antral biopsy. This showed a mild atrophic gastritis also with Campylobacter like organisms present. Apart from this single case all other abnormal antral biopsies were negative for Campylobacter like organisms $(15 / 16)$ (Table 1). In the 25 follow up biopsies at five years no significant histological modification was observed in the body or antral biopsies (Table 2), and the same single patient was again found to be positive for Campylobacter like organisms in both body and antrum.

\section{Discussion}

Campylobacter like organisms were identified on 
microscopy in only three of 86 patients with pernicious anaemia. It is clear that these bacteria only rarely colonise the abnormal body in pernicious anaemia and are unlikely to be involved in the pathogenesis of the disease. ${ }^{10}{ }^{11}$ In those patients with antral and body biopsies the figure is one of 44 patients. If the observations are restricted further to only patients with abnormal antral mucosae, then the frequency of Campylobacter like organisms is one of 16 patients $(6 \cdot 5 \%)$. This figure is well below that for the frequency of Campylobacter pylori in the hospital population with gastritis not caused by pernicious anaemia $^{31215}$ and even below the carriage level for gastritis found incidentally amongst symptomless controls. ${ }^{1617}$

Before considering the significance of this result, it is pertinent to examine the available data on the pathology of the antrum in pernicious anaemia. The classification of gastritis is broadly in three patterns. ${ }^{46}$ Type $\mathrm{A}^{4}$ corresponds approximately to autoimmune gastritis ${ }^{5}$ and predominantly affects the body of the stomach. Type $\mathrm{B}^{4}$ relates to hypersecretory gastritis ${ }^{5}$ that predominantly involves the antrum with variable proximal spread. This is the pattern associated with peptic ulcer disease in general, and duodenal ulceration in particular. The third pattern environmental chronic gastritis ${ }^{5}$ is the type seen in high incidence areas of gastric cancer. It may correspond to the AB type. ${ }^{6}$ Topographically it is multifocal and centred along the junction of antrum and body. Most of the studies on Campylobacter pylori and gastritis have been on the type B or hypersecretory pattern. ${ }^{1-3} 12$ is Type $\mathrm{A}$ or autoimmune gastritis, the form associated with pernicious anaemia, is believed to spare the antrum. ${ }^{4}$ As Campylobacter pylori rarely colonises the normal antrum, ${ }^{12}$ this would seem an adequate explanation for their absence in pernicious anaemia. From our results, however, and several other studies it is clear that the antrum can be abnormal in pernicious anaemia. Indeed Lewin $e t$ al $l^{18}$ claim the antrum to be invariably abnormal, Stockbrugger et al ${ }^{19}$ quote an incidence of $21 \%$ for antral inflammation whilst Kekki et ${ }^{20}{ }^{20}$ suggest the changes in the antrum are dynamic. Thus early on in the natural history of pernicious anaemia antral gastritis is common but Kekki et al claim there is a return to normality as fully established gastric atrophy develops in the body. These reports ${ }^{18-20}$ do not make it clear whether the antral involvement is all part of the pattern of type $A$ gastritis or is merely coincidental development of type B gastritis. Day ${ }^{21}$ and Owen ${ }^{22}$ favour the latter suggestion. Whichever is the correct interpretation, in this study $36 \%$ of patients with pernicious anaemia were found to have antral gastritis. The failure to find any changes in the degree of gastritis in those patients who were followed up and biopsied at five years argues against Kekki et al's hypothesis. ${ }^{20}$

Several factors might contribute to the low frequency of Campylobacter pylori found in pernicious anaemia, be it in the antrum or body. The simplest explanation is that the aetiology of the antral gastritis in patients with pernicious anaemia is the same as that in the body, namely an autoimmune one, and that Campylobacter pylori has no role at either site. On the other hand there was no apparent histological difference in the antral gastritis seen here as part of the picture of pernicious anaemia and that seen in the more common type B pattern. ${ }^{3}$ Special stains to detect changes in lymphocyte subpopulations or other immunological differences were, however, not carried out. A clinical difference observed was that the patients with antral disease were older than those with a normal antrum. This is a point in favour of the antral involvement being a superimposed type B or hypersectory gastritis, as is finding the frequency of antral gastritis to be $36 \%$ which is similar to that of type B gastritis in randomly selected populations. ${ }^{23}$ Set against this are the data from those patients who were rebiopsied at five years. These might have been expected to show increased antral abnormalities but this was not the case. Another explanation for the rarity of Campylobacter pylori in pernicious anaemia might be on the basis of widespread intestinal metaplasia, for Campylobacter pylori do not associate with this mucosal pattern. ${ }^{24} 25$ This seems unlikely here as intestinal metaplasia in the antrum was widespread in only three cases (Table 1). Few of the biopsies showed activity in the form of neutrophils infiltrating the surface epithelium and gastric pits. Some workers ${ }^{12}$ suggest the frequency of organisms correlates with this activity but the differences in colonisation frequency seen here are too great for this explanation. Moreover, not all investigators acknowledge this correlation. ${ }^{23}$

Irrespective of whether the antral gastritis in pernicious anaemia is an extension of an autoimmune process into the antrum or a superimposed pattern of hypersecretory (type B) gastritis the frequency of Campylobacter like organisms in the involved antrum is still well below that found in control groups. ${ }^{16}{ }^{17}$ Therefore, the antrum in pernicious anaemia appears to be susceptible to gastritis but not to colonisation by Campylobacter pylori; a suggestion reinforced by the absence of any change in the incidence of colonisation in the patients rebiopsied after five years and given the ubiquitous nature of the organism. ${ }^{2} 3152426$

Contrasting situations are seen therefore between duodenal ulcer disease and pernicious anaemia in relation to Campylobacter pylori status. In patients with duodenal ulcer disease acid levels are high and 
up to $90 \%$ of patients exhibit antral gastritis associated with the organisms. ${ }^{326}$ In this situation the duodenal mucosa is also colonised if there is gastric metaplasia. ${ }^{26}$ On the other hand in patients with pernicious anaemia acid is absent, and even when antral gastritis is present, as shown here, there is almost a total absence of Campylobacter pylori. Moreover the frequency of Campylobacter pylori is low in patients with bile reflux which too might reflect neutralisation of gastric acid. ${ }^{9}$ Thus situations in which antral $[\mathrm{pH}]$ is likely to be raised are those in which Campylobacter pylori are absent and viceversa. The mechanism may simply reflect competitive exclusion of Campylobacter pylori by other bacteria which are known to colonise the stomach in large numbers once the $[\mathrm{pH}]$ rises. ${ }^{27}$ Conditions for antral colonisation seem unlikely to depend directly on acid and a low [pH]. Campylobacter pylori are inhibited by acid though can survive a $[\mathrm{pH}]$ of 2.6 in the presence of urea $^{28}$ but their urease activity ${ }^{29}$ is inhibited below a $[\mathrm{pH}]$ of $4 \cdot 5 .{ }^{30}$ Furthermore the bacteria are closely associated with the epithelial cell surface which is below the mucus layer ${ }^{325}$ and therefore protected from acid exposure. In addition periods of hypoacidity seem a necessary part of experimental colonisation susceptibility in $\operatorname{man}^{7}$ as well as being a feature of epidemic outbreaks. ${ }^{3132}$ Finally, $\mathrm{H}_{2}$ antagonists fail to eliminate the organisms. ${ }^{33}$ Thus gastric acidity at the most only contributes to a suitable environment for Campylobacter pylori, or at the least is simply a marker of some other function of the gastric body mucosa essential to the organisms successful antral association. Indeed there are data suggesting that antral colonisation might be dependent on the integrity of the gastric body mucosa. ${ }^{34}$

In conclusion we have shown that antral gastritis unassociated with Campylobacter like organisms occurs in the type A or autoimmune gastritis of pernicious anaemia. It is possible that the former is immune mediated and represents the same process as in the gastric body. On the other hand, the antral involvement may represent superimposed hypersecretory or type B gastritis. This would seem unlikely unless either Campylobacter pylori is merely an opportunist and the antrum in pernicious anaemia resistent to colonisation, or that the gastric environment in pernicious anaemia selects out that small percentage of patients found in studies of type $B$ gastritis $^{23152426}$ that have no associated Campylobacter pylori and for whom another aetiology must be found.

We thank Drs $\mathbf{P}$ Borriello, $\mathrm{U}$ Armbrecht and $\mathbf{P}$ Cotton for their help and advice. Dr J-F Flejou acknowledges the help of a British Council grant.

\section{References}

1 Marshall BJ, Warren JR. Unidentified curved bacilli in the stomach of patients with gastritis and peptic ulceration. Lancet 1984; i: 1311-5.

2 Jones DM, Lessels AM, Eldridge J. Campylobacter like organisms on the gastric mucosa: Culture, histological and seriological studies. J Clin Pathol 1984; 37: $1002-6$.

3 Price A, Levi J, Dolby JM, et al. Campylobacter pyloridis in peptic ulcer disease: microbiology, pathology and scanning electron microscopy. Gut 1985; 26: 1183-8.

4 Strickland RG, Mackay IR. A reapparaisal of the nature and significance of chronic atrophic gastritis. Am J Dig Dis 1972; 18: 426-40.

5 Correa $P$. The epidemiology and pathogenesis of chronic gastritis: three etiologic entities. Front Gastrointestinal Res 1980; 6: 98-108.

6 Glass GBJ, Pitchumoni CS. Atrophic gastritis. Hum Pathol 1975; 6: 219-50.

7 Marshall BJ, Armstrong JA, McGechie DB, Glancy RJ. Attempt to fulfil Koch's postulates for pyloric campylobacter. Med J Aust 1985; 142: 436-9.

8 Krakowa S, Morgan DR, Kraft WG, Leunk RD. Establishment of gastric Campylobacter pylori infection in the neonatal gnotobiotic pig. Infect Immun 1987; 55: 2789-96.

9 O'Connor HJ, Wyatt JI, Dixon MF, Axon ATR. Campylobacter like organisms and reflux gastritis. J Clin Pathol 1986; 39: 531-4.

10 O'Connor HJ, Axon ATR, Dixon MF. Campylobacter like organisms unusual in Type A (Pernicious Anaemia) gastritis. Lancet 1984; ii: 1091.

11 Gonzalez Juan D, Sancho FJ, Sainz S, Such J, Fernandez M, Monez Xiol J. Campylobacter pylori and pernicious anaemia. Lancet $1988 ;$ i: 57.

12 Wyatt JI. Rathbone BJ, Heatley RV. Local immune response to gastric Campylobacter in non-ulcer dyspepsia. J Clin Pathol 1986; 39: 863-70.

13 Burnett RA, Brown IL, Findlay J. Cresyl-fast violet staining method for Campylobacter-like organisms. J Clin Pathol 1987; 40: 353.

14 Whitehead R, Truelove SC, Gear MWL. The histological diagnosis of chronic gastritis in fibreoptic gastroscope biopsy specimens. J Clin Pathol 1972; 25: 1-11.

15 McNulty CAM, Gearty JC, Crump B, et al. Campylobacter pyloridis and associated gastritis. Investigator blind placebo controlled trial of bismuth salicylate and erythromycin ethylsuccinate. Br Med J 1986; 296: 645-9.

16 Flejou J-F, Price AB, Smith AC, Owen ER. Campylobacter pylori and gastric manipulation for morbid obesity. Lancet 1987; ii: 917-8.

17 Langenberg ML, Tytgat GWJ, Schipper MEI, Rietra PGM, Zanen HC. Campylobacter like organisms in the stomach of patients and healthy individuals. Lancet 1984; i: 1348.

18 Lewin KJ, Dowling F, Wright JP, Taylor KB. Gastric morphology and serum gastrin levels in pernicious anaemia. Gut 1976; 17: 551-60.

19 Stockbrugger RW, Menon GG, Beilby JOW, Mason RR, Cotton PB. Gastroscopic screening in 80 patients with pernicious anaemia. Gut 1983; 24: 1141-7. 
20 Kekki M, Varis K, Pohjanpola H, Isokoski M, Ihamaki $\mathrm{T}$, Siurala M. Course of antrum and body gastritis in pernicious anaemia families. Dig Dis Sci 1983; 28: 698704.

21 Day DW. Biopsy pathology of the oesophagus, stomach and duodenum. London: Chapman and Hall, 1986: 10110.

22 Owen DA. Gastritis and duodenitis. In: Appelman HD, ed. Pathology of the oesophagus, stomach and duodenum. New York: Churchill Livingstone, 1984: 37-77.

23 Strickland RG. Chronic gastritis. In: Bouchier IAD, Allan RN, Hodgson HFJ, Keighley MRD, eds. Textbook of gastroenterology. London: Baillière Tindall, 1986: 113-25.

24 Johnston BJ, Reed PI, Ali MH. Campylobacter like organisms in duodenal and antral endoscopic biopsies: relationship to inflammation. Gut 1986; 27 : 1132-7.

25 Steer HW. The gastro-duodenal epithelium in peptic ulceration. J Pathol 1985; 146: 355-62.

26 Wyatt J, Rathbone BJ, Dixon MF, Heatley RV. Campylobacter pyloridis and acid-induced gastric metaplasia in the pathogenesis of duodenitis. J Clin Pathol 1987; 40: 841-8.
27 Borriello SP, Reed PJ, Dolby JM, Barclay FE, Webster ADB. Microbial and metabolic profile of achlorhydric stomach: comparison of pernicious anaemia and hypogammaglobulinaemia. J Clin Pathol 1985; 38: 946-53.

28 Tompkins DS, West AP. Campylobacter pylori, acid, and bile. J Clin Pathol 1987; 40: 1387.

29 Hazell SL, Lee A. Campylobacter pyloridis, urease, hydrogen ion back diffusion and gastric ulcers. Lancet 1986; ii: $15-7$.

30 Taylor M, Karim QN. Urease activity of Campylobacter pylori. J Clin Pathol 1988; 41: 112.

31 Ramsay EJ, Carey KV, Peterson WL, et al. Epidemic gastritis with hypochlorhydria. Gastroenterology 1979; 76: $1449-57$.

32 Goodwin CS, Armstrong JA, Marshall BJ. Campylobacter pyloridis, gastritis, and peptic ulceration. J Clin Pathol 1986; 39: 353-65.

33 Coghlan JG, Gilligan D, Humphries D, et al. Campylobacter pylori and recurrence of duodenal ulcers - a 12 month follow-up study. Lancet 1987; ii: 1109-11.

34 Siurala M, Sipponen P, Kekki M. Campylobacter pylori in a sample of Finnish population: relations to morphology and function of the gastric mucosa. Gut 1988; 29: 909-15. 